\title{
Evaporation Heat Transfer Coefficients Of R-446A And R-1234ze(E)
}

\author{
Minsoo Kim ${ }^{1}$ and Keumnam Cho ${ }^{2 *}$ \\ ${ }^{1}$ Graduate School of Mechanical Engineering, Sungkyunkwan University \\ Seobu-Ro, 2066, Jangan-gu, Suwon, Korea, starsteam1@ @sku.edu \\ ${ }^{2 *}$ School of Mechanical Engineering, Sungkyunkwan University \\ Seobu-Ro, 2066, Jangan-gu, Suwon, Korea, keumnamcho@skku.edu
}

\begin{abstract}
The present study investigated evaporation heat transfer coefficients and pressure drops of R-446A and R-1234ze(E). The heat transfer coefficients were investigated by measuring wall temperature on a straight stainless tube with an inner diameter of $7.4 \mathrm{~mm}$ and a length of $1.3 \mathrm{~m}$ and refrigerant temperature estimated by using refrigerant pressure. The test apparatus was consisted of an evaporator tube, a pump, a constant temperature bath, a pre-heater, a condenser, a DC power supply, measuring devices, etc. Sightglasses were installed at the inlet and outlet of test section to monitor flow regime. The heat transfer coefficients were measured for the quality from 0.1 to 0.9 , the mass flux from 100 to $400 \mathrm{~kg} / \mathrm{m}^{2} \mathrm{~s}$, the heat flux of 10 to $30 \mathrm{~kW} / \mathrm{m}^{2}$, and the saturation temperature from 5 to $10^{\circ} \mathrm{C}$. The effect of mass flux on the evaporation heat transfer coefficient was not much at low quality, while it was relatively large at high quality. The heat transfer coefficients of R-446A were mostly larger by approximately $16 \%$ than those of R-410A, while heat transfer coefficients of R-1234ze(E) were about 3\% lower than those of R134a. Pressure drops of R-446A were larger by approximately 30\% than those of R-410A, while pressure drops of R-1234ze(E) were about 20\% higher than those of R134a. Correlation predicted the heat transfer coefficients of R-446A with the deviation of $45 \%$ and those of R-1234ze with the deviation of 26\%. Pressure drop correlation showed the deviation of $30 \%$ for R-446A and $40 \%$ for R-1234ze(E).
\end{abstract}

Keywords: evaporation, heat transfer coefficient, pressure drop, R-446A, R-1234ze(E)

\section{Introduction}

HFC-410A is about to be replaced with low GWP refrigerant such as HFO-446A, HFO-447A due to its high GWP, even though it has been used for the last couple of decades as HCFC-22 substitute for the refrigeration and air-conditioning system.

HFC-134a is about to be replaced with HFO-1234ze(E) with low GWP for the turbo chiller, even though it has been replaced with HFO-1234yf with low GWP for the automobile air-conditioner. HFO refrigerants such as HFO-446A and HFO-1234ze(E) have been investigated as the alternative refrigerants with low GWP.

The present study measured evaporation heat transfer coefficients and pressure drop characteristics of them that are essential to design the evaporator.

\section{Experimental Apparatus}

The experimental apparatus is schematically shown in Fig. 1. The test apparatus consisted of a test section, a condenser, a refrigerant pump, a receiver, a mass flow meter, a preheater, and measuring devices. The test section was a horizontal stainless steel tube with an inner diameter of $7.4 \mathrm{~mm}$ and the length of $1300 \mathrm{~mm}$. Outside wall temperature of the tube was measured along the tube by $42 \mathrm{~T}$ type thermocouples. Refrigerant pressure was measured by absolute pressure gauge at the inlet, outlet, and three middle points with the same interval of the evaporator.

Flow pattern of the refrigerant was observed by a sight glass installed at inlet and outlet of the test section. The preheater controlled the inlet vapour quality of the refrigerant by heating the refrigerant in front of the test section. Refrigerant passed through the test section was condensed by the condenser and then flowed into the receiver. The refrigerant pump circulated the refrigerant. 


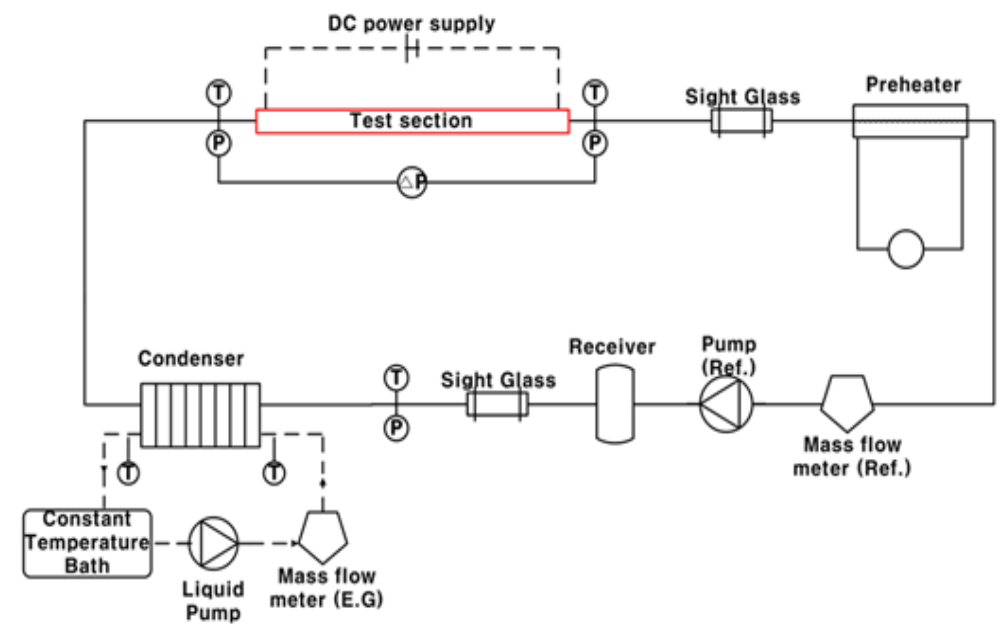

Fig. 1: Experimental Apparatus.

Heat transfer coefficient was calculated by using the following equations.

$$
\begin{gathered}
\mathrm{q}=\mathrm{hA}\left(T_{w i}-T_{s a t}\right) \\
T_{w i}=T_{w o}-\frac{\ln \frac{r_{w o}}{r_{w i}}}{2 \pi k L} \cdot q
\end{gathered}
$$

\section{Result and discussion}

\subsection{Heat transfer coefficient}

Figure 2 shows the effect of mass flux and heat flux on the heat transfer coefficient of R-446A.
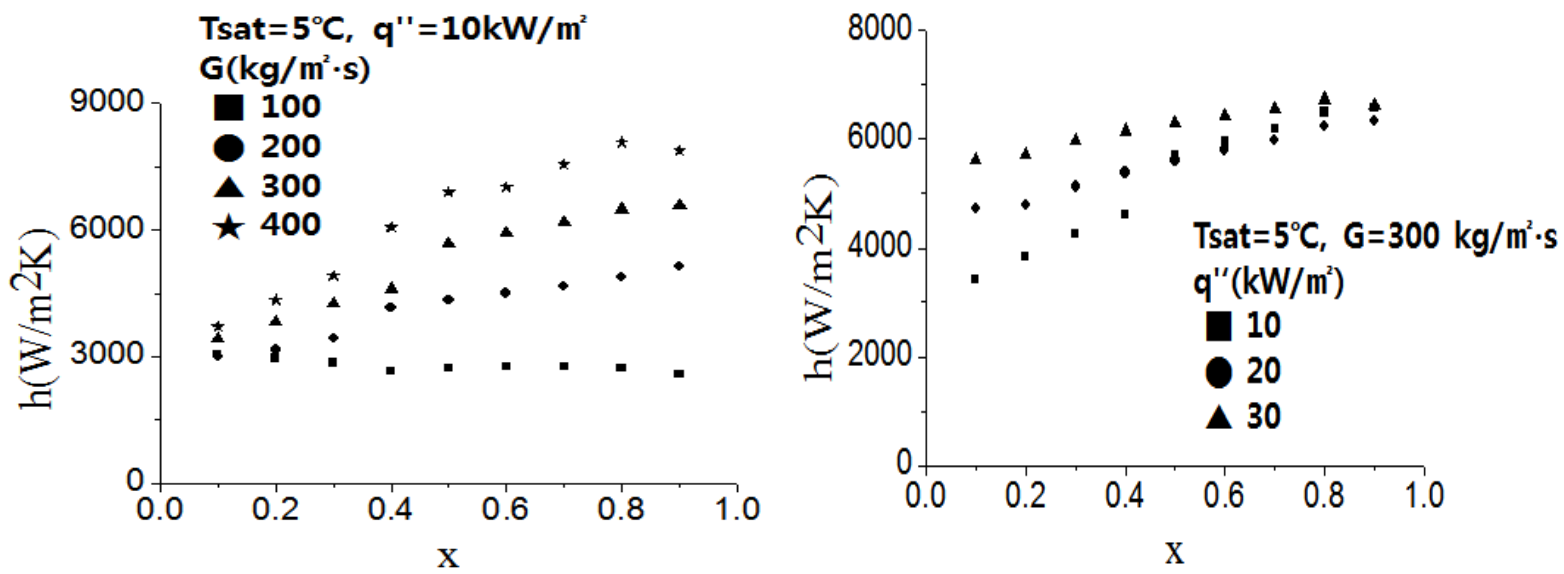

Fig. 2: Effect of mass flux and heat flux on the heat transfer coefficients of R-446A.

The heat transfer coefficients increased with increasing the refrigerant mass flux. For the high mass flux condition, nucleate boiling suppression appeared earlier. This means that convective heat transfer appeared earlier under the high mass flux condition. Nucleate boiling is dominant at the initial stage of evaporation. The large effect of heat flux on the heat transfer coefficient shows the dominance of nucleate boiling heat transfer contribution. At the high quality region, nucleate boiling was suppressed, and the effect of heat flux on the heat transfer coefficient was getting lower.

Figure 3 shows the effect of mass flux and heat flux on the heat transfer coefficient of R-1234ze(E). The effect of heat flux and mass flux on the heat transfer coefficient was similar with that of R-446A. 

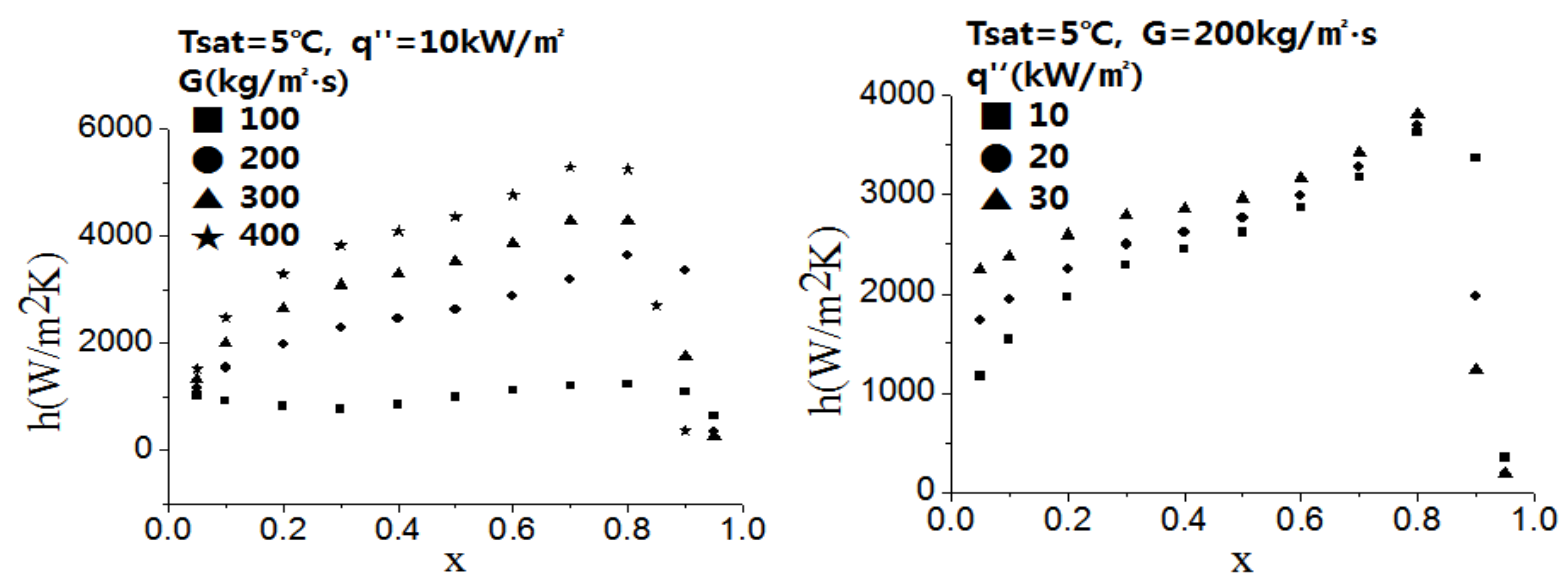

Fig. 3: Effect of mass flux and heat flux on the heat transfer coefficients of R-1234ze(E).

Figure 4 shows the comparison of heat transfer coefficient of R-446A and R-410A. Heat transfer coefficients of R446A were higher by $16 \%$ than those of R-410A. Since the liquid and vapour densities of R410A were larger than those of $\mathrm{R}-446 \mathrm{~A}$, fluid velocity of R-446A is higher than that of R-410A under constant mass flux condition. Dominance of convective boiling for R-446A was appeared at a low quality.

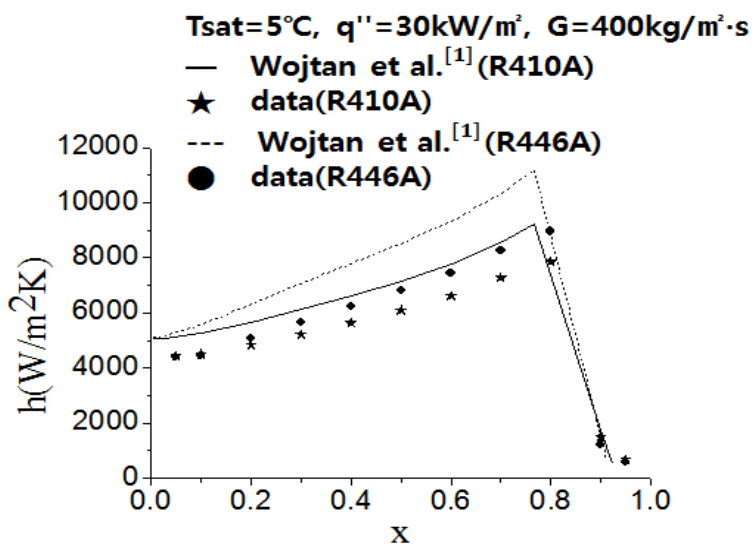

Fig. 4: Comparison of heat transfer coefficients of R-410A and R-446A.

Typical properties of Refrigerants are shown in Table 1.

Table 1: Properties of Refrigerants at Tsat of $5^{\circ} \mathrm{C}$.

\begin{tabular}{|l|l|l|l|l|}
\hline Property & R-410A & R-446A & R-134a & R-1234ze $(\mathrm{E})$ \\
\hline Saturation pressure & $936.23 \mathrm{kPa}$ & $854.28 \mathrm{kPa}$ & $349.66 \mathrm{kPa}$ & $259.34 \mathrm{kPa}$ \\
\hline Liquid density $\left(\mathrm{kg} / \mathrm{m}^{3}\right)$ & 1149.6 & 1058 & 1278.1 & 1225.4 \\
\hline Vapour density $\left(\mathrm{kg} / \mathrm{m}^{3}\right)$ & 35.219 & 25.089 & 17.131 & 13.923 \\
\hline Liquid viscosity $(\mu \mathrm{Pa} \cdot \mathrm{s})$ & 151.86 & 153.47 & 250.11 & 253 \\
\hline Vapour viscosity $(\mu \mathrm{Pa} \cdot \mathrm{s})$ & 12.462 & 11.795 & 10.911 & 11.398 \\
\hline Surface tension $(\mathrm{mN} / \mathrm{m})$ & 8.2984 & 11.039 & 10.73 & 11.497 \\
\hline
\end{tabular}

Correlation by wojtan et al. ${ }^{[1]}$ predicted the heat transfer coefficients of R-446A with the deviation of $45 \%$, and the heat transfer coefficients of R-410A lower by $20 \%$ than the measured data. 
Figure 5 shows the comparison of heat transfer coefficient of R-134a and R-1234ze(E). Heat transfer coefficients of R-134a were slightly higher than those of R-1234ze(E). Since liquid and vapour densities of R-134a are large, fluid velocity of R-1234ze(E) was higher than that of R-134a at constant mass flux. It causes dominance of convective boiling and large heat transfer coefficient. Pressure of R-134a is generally higher than that of R-1234ze(E). At large pressure, bubble frequency increased with the decrease of bubble departure diameter. It contributed to the increase of the heat transfer coefficient. The heat transfer coefficients of R-134a were slightly higher than those of R-1234ze(E)

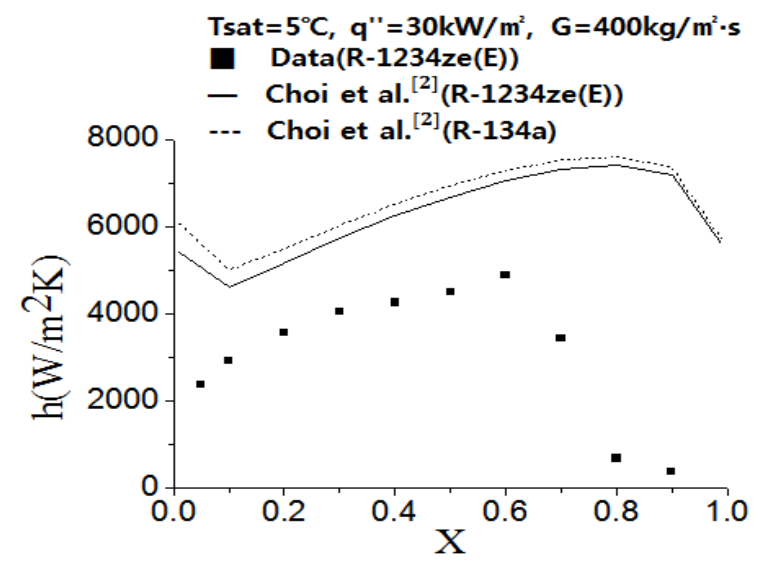

Fig. 5: Comparison of heat transfer coefficients of R-134a and R-1234ze(E).

Correlation by Choi et al. ${ }^{[2]}$ predicted the heat transfer coefficients of R-1234ze(E) with the deviation of $30 \%$, and the heat transfer coefficients of R-134a lower by $20 \%$ than the measured data.

\subsection{Pressure drop}

Figure 6 shows the comparison of pressure drop of R-410A and R-446A. Pressure drops of R-446A were larger by approximately $30 \%$ than those of R-410A. Since the density ratio of liquid and vapour of R-446A is higher than that of R410A, interfacial shear stress of R-446A is higher than that of R-410A.

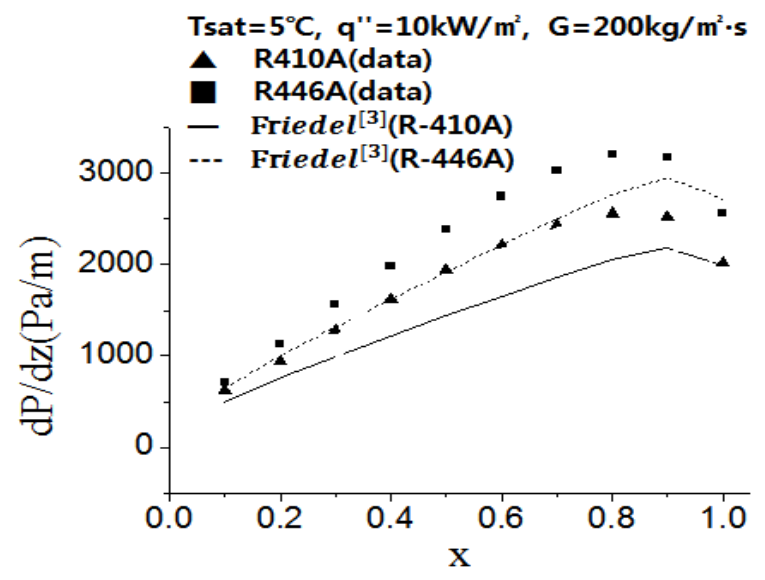

Fig. 6: Comparison of Pressure drop of R-410A and R-446A.

Pressure drop predicted by the Friedel ${ }^{[3]}$ correlation showed the deviation of $30 \%$ from the measured data for R-446A.

Figure 7 shows the comparison of pressure drop of R-134a and R-1234ze(E). Pressure drops of R-1234ze(E) were larger by approximately $20 \%$ than those of R-134a. Since the density ratio between liquid and vapour of R-1234ze(E) is higher than that of R-134a, interfacial shear stress of R-1234ze(E) is higher than that of R-134a. 
Pressure drop predicted by the Friedel ${ }^{[3]}$ correlation showed the deviation of $40 \%$ from the measured data for R1234ze(E).

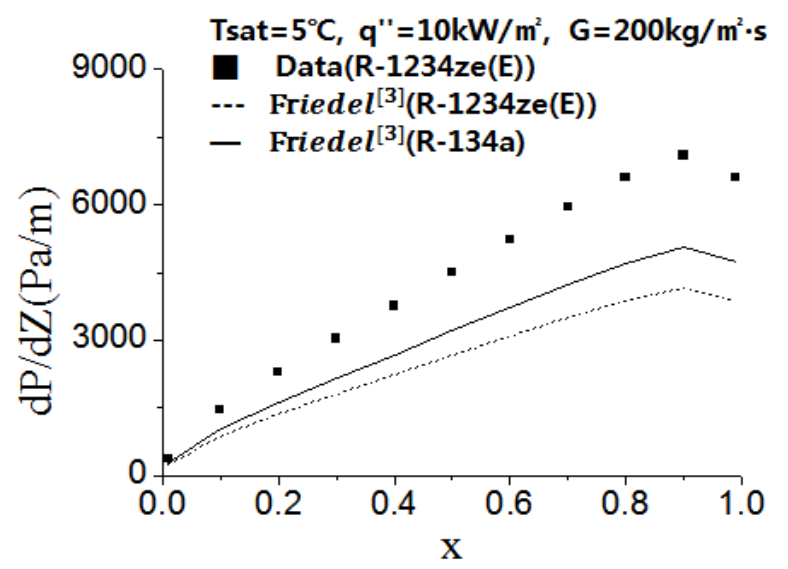

Fig. 7: Comparison of Pressure drop of R-134a and R-1234ze(E).

\section{Conclusions}

The heat transfer coefficients of R-446A were larger by approximately $16 \%$ than those of R-410A, while The heat transfer coefficients of R-1234ze(E) were lower by 3\% than those of R134a. Pressure drops of R-446A were larger by approximately $30 \%$ than those of R-410A, while the pressure drops of R-1234ze(E) were larger by $20 \%$ than those of R134a.

Wojtan et al. ${ }^{[1]}$ correlation predicted the heat transfer coefficients of R-446A with the deviation of $45 \%$, while Choi et al. ${ }^{[2]}$ correlation predicted the heat transfer coefficients of R-1234ze(E) with the deviation of 30\%. Pressure drop correlation predicted by Friedel ${ }^{[3]}$ correlation showed the deviation of $30 \%$ for R-446A and $40 \%$ for R-1234ze(E).

\section{Acknowledgements}

This work was supported by the Technology Innovation Program(10052926, Development of Core Technologies for Low GWP Refrigerant System) funded by the Ministry of Trade, Industry\&Energy(MI, Korea).

\section{References}

[1] L. Wojtan, T. Ursenbacher and J. R. Thome., "Investigation of flow boiling in horizontal tubes: Part 1- A new diabatic two-phase flow pattern map," Int. J. Heat and Mass Transfer, vol. 48, pp. 2955-2969, 2005.

[2] T. Y. Choi, Y. J. Kim, M. S. Kim, and S. T. Ro., "Evaporation heat transfer of R-32, R-134a, R-32/134a, and R32/125/134a inside a horizontal smooth tube," Int. J. Heat and Mass Transfer, vol. 43, pp. 3651-3660, 2000.

[3] L. Friedel, "Improved friction pressure drop correlations for horizontal and vertical two-phase pipe flow," European Two-Phase Flow Group Meeting, Italy, Ispra, 1979, Paper E2. 